\title{
0 que são ideais ascéticos? Dogville: a imagem invertida
}

What are Ascetical Ideals?

Dogville: the Inverted Image

\section{Vânia Dutra de Azeredo \\ Departamento de Filosofia - Unirio}

\section{RESUMO}

Neste artigo, utilizaremos os conceitos nietzschianos de ideais ascéticos, ressentimento e moral de rebanho visando mostrar o entrelaçamento apontado por Nietzsche entre humanidade e doença a partir de uma leitura do filme Dogville de Lars Von Trier.

\section{PALAVRAS-CHAVE}

Ideais ascéticos; Ressentimento; Moral de rebanho; Humanidade; Doença.

\begin{abstract}
In this article, we use the Nietzschean concepts of ascetical ideals, resentment and moral of the flock aiming to show the interlacing pointed by Nietzsche between humanity and sickness starting from a reading of the movie Dogville from Lars Von Trier.
\end{abstract}

\section{KEY WORDS}

Ascetical Ideals; Resentment; Moral of the Flock; Humanity; Sickness. 
Motivos aliviam...

Nietzsche

Neste artigo, partindo da relação entre os conceitos de ideais ascéticos, moral de rebanho e ressentimento, visamos mostrar a impossibilidade de uma formulação afirmativa do humano em Nietzsche, já que o ingresso do homem no âmbito da sociedade e da paz é promotor do desenvolvimento de uma vingança inconfessável que termina por inviabilizar que se atribua, por condição, às noçôes de solidariedade e de filantropia aos seres humanos vivendo em conjunto. Ao contrário disso, proporemos, desde Nietzsche, uma ligação entre doença e humanidade. A fim de mostrar tal entrelaçamento, aplicaremos os conceitos nietzschianos ao argumento de Lars Von Trier no filme Dogville. A leitura da crítica de Daniel Delfino sobre o filme exerceu influência em nosso argumento, todavia, dela nos distanciamos quando o autor enfatiza a sociedade de classes como móvel da problemática humana, pois, em nossa avaliação, ela se encontra na reunião dos homens, independentemente da organização e da divisão social, tornando pertinente a aplicação dos conceitos nietzschianos.

Comecemos com a definição de ideal ascético ${ }^{\mathrm{I}}$ apresentada por Nietzsche enquanto um instinto não satisfeito que funciona em contradição com vontade de vida, já que tem sua origem numa vida que se degenera e que vê nesse ideal a única maneira de se conservar, fazendo da negação da vida um meio de combate, não contra a vida, mas contra a morte enquanto modo de preservar a vida. Há um processo degenerativo e o ideal ascético é o artifício encontrado para o estancar; um recurso ao qual se agarram determinados tipos que lutam pela existência. São os impulsos que ainda não se degeneraram que atuam, que propriamente buscam a preservação. Em vista disso, a negação constituir-se como meio de sobrevivência e forma de manutenção. Há de se observar, ainda assim, que tipo de vida existe e o que quer através desse ideal, o que não impede que se perceba com estranheza esse meio encontrado, justamente por ele não só conservar como propagar o estado de degenerativo através da negação da força, da efetividade e de toda afirmação.

Pois uma vida ascética é uma autocontradição; aqui domina um ressentimento raro, o de um insaciado instinto e vontade de potência, que gostaria de se tornar senhor, não sobre algo na vida, mas sobre a própria vida, sobre suas mais profundas, mais fortes, mais básicas condições, aqui é feito um ensaio de usar a força para estancar fontes

I A exposição conceitual dos ideais ascéticos apresentada neste artigo remete a um estudo anterior sobre a temática da genealogia da moral em Nietzsche publicado no livro Nietzsche e a dissolução da moral (cf. Azeredo, 2003). 
da força; aqui se dirige o olhar verde e maligno, contra sua expressão, a beleza, alegria; enquanto no malograr, no enfezar, na dor, no desastre, no feio, na penitência voluntária, na negação de si, na autoflagelação, no auto-sacrifício, uma satisfação é sentida e procurada. ${ }^{2}$

Lutar contra a própria vida e, ao mesmo tempo, retirar dessa luta a maneira de preservar a vida é a contradição de que o filósofo fala. Na vida ascética domina um instinto não satisfeito, um ressentimento que se volta contra tudo que é forte e próspero. Somente o sofrimento e a doença são procurados, chegando a instituir o sofrimento como algo que satisfaz e revigora. A força, nesse caso, visa ao aniquilamento da força. No querer transmutar o afirmativo em negativo, percebe-se a presença da negação como movente. Daí sua aversão ao que é belo e alegre, em suma, ao próprio prosperar fisiológico. O paradoxo ao qual Nietzsche se refere fica determinado pelo querer mesmo. O que quer essa vontade de potência? Quer dominar: "O triunfo precisamente na última agonia: sob esse signo superlativo combateu desde sempre o ideal ascético; nesse enigma de sedução, nessa imagem de delícia e tormento reconheceu ele sua mais clara luz, sua salvação, sua vitória final". ${ }^{3}$ A própria cisão aqui é querida e desejada, já que revigora ao mesmo tempo em que degenera.

Em condiçôes de doença, esse ideal propaga-se, manifestando-se historicamente porque o homem está doente dele mesmo e o ideal aparece como um meio de manutenção e de suportabilidade da existência, através da percepção dela como imagem invertida: um Deus universal e um além-mundo em oposição à essa vida e a esse mundo, incluindo ainda como forma de imagem invertida a busca desenfreada de perfeição seja na vida e ou na obra, seja na comunidade, em torno de objetivos comuns ideados por um líder, tomado, por nós, como sacerdote ascético, ainda que não seja sacerdote. Nietzsche o apresenta historicamente como o sacerdote judeu e o padre cristão, mas, em nossa avaliação, o tipo sacerdote ascético encaixa-se em outras figuras culturais que lideram o rebanho, quer dizer, a associação de tipos que precisam desembaraçar-se da fraqueza e do desprazer canalizando-os para uma atividade comum aparentemente frutífera e, quiçá, ornamentativa. A questão identificada por Nietzsche e aplicada por nós para compreender Dogville está: "No desejo de se desembaraçar do seu desprazer surdo e de seu sentimento de fraqueza, todos os doentes, todos os doentios, tendem instintivamente a se organizar em rebanho: o padre ascético intui esse instinto e o encoraja". ${ }^{4}$

2 Genealogia da Moral, "Terceira dissertação", \$ II, KSA 5.363. Tradução conforme Rubens Rodrigues Torres Filho (Nietzsche, 1978). A partir de agora indicado como RRTF.

3 Genealogia da Moral, "Terceira dissertação", \$ II, KSA 5.363, tradução de RRTF.

4 Genealogia da Moral, "Terceira dissertação", $\$$ I8, KSA 5.384, tradução de RRTF. 
A organização em rebanhos guarda a tentativa de dirimir a impotência mediante o sentimento de ver a comunidade prosperar. Ao negar o que difere se obtêm uma pretensa afirmação de força e, com isso, um sentimento de elevação mediante as relações associativas. Todavia, são os fracos que assim procedem, indicando a fraqueza como dominante na associação, ainda que esteja presente nessa união o afeto fundamental, isto é, a vontade é mantida e o desespero amortecido pela transposição da dor individual na alegria do prosperar da comunidade. A habilidade maior do sacerdote fica determinada pela seleção de meios que aliviem o sofrimento e pelo controle exercido sobre a vontade, prescrevendo sempre doses prudentes de sua expressão, de modo a manter o controle sobre o rebanho.

A descarga do afeto permite o entorpecimento, enquanto produtor de uma emoção intensa que tem como efeito a suspensão do mal-estar. Em vista disso, a necessidade dessa descarga, possibilitada pela projeção do outro como culpado. Porém, o descontrole que poderia advir com isso faz com que o sacerdote introduza uma nova compreensão da culpa, qual seja, a culpa como responsabilidade do próprio agente e não de outrem. O sacerdote ascético introduz a noção de pecado, segundo a qual os males seriam provenientes de faltas cometidas no passado, para que a culpa seja assimilada. A dor seria uma consequência disso, um castigo pela falta cometida, afinal, se um homem está mal é porque pecou.

Ao introduzir a culpa/falta, a dor torna-se produto dessa falta. Interiorizar a força produzia dor, mas com a culpa processa-se a interiorização dessa dor: dor como resultado da falta. O que o sacerdote combate é o sofrimento, não a sua causa, por isso, não poder ser médico, embora deseje tal designação. Não obstante, o sacerdote, assim como o ideal por ele propagado, tem uma função em termos de assimilação da existência. A construção de seu ideal visa à preservação da vontade. $\mathrm{O}$ sacerdote assume como missão cuidar de uma vida que se degenera, que, para sobreviver, precisa de uma justificação, de um sentido, em suma, de um ideal. Sendo desejo manifesto de ser outro e de estar em outro lugar, o sacerdote constrói as condições necessárias para a viabilidade do querer nesse mundo mesmo, ainda que transferindo a satisfação, a plenitude e o bem-estar para outra dimensão: "mas justamente a potência de seu desejar é a cadeia que o prende; justamente com isso ele se torna instrumento, que tem de trabalhar para criar condiçôes mais favoráveis para o estar-aqui e ser-homem...". Colocando o cristianismo como um sentido para a dor, o sacerdote encontra os meios adequados para aliviar a alma humana cindida.

Nesse momento analisaremos o filme Dogville de Lars Von Trier a partir dos conceitos nietzschianos a fim de mostrar como sem dificuldades e sem resistências

5 Genealogia da Moral, "Terceira dissertação", $\$$ I3, KSA 5.366, tradução de RRTF. 
abandonamos todo humanismo, toda filantropia, toda solidariedade e toda compreensão, deixando-nos atravessar pela Santa Ira, isto é, uma ira que se justifica pela maldade do outro, requerendo a destruição dele, em vista disso ser uma ira Santa. Com ela em mãos, dissolvemos nossos conceitos mais caros, levando com a dissolução deles os baluartes de nossa pretensa civilidade, permitindo-nos abandonar nosso amor pela humanidade e deixando-nos transformar em cães raivosos prontos a abater o próximo e o distante.

A nosso ver, há muita originalidade em termos cinematográficos no filme Dogville. Com relação ao cenário, vemos o abandono das convenções presentes na maior parte dos filmes, pois não há efetivamente uma cidade, nem casas, nem ruas, nem portas, nem árvores, tudo é desenhado com giz em um piso negro, lembrando-nos mais a narrativa teatral do que a cinematográfica. Isso nos permite perceber, ainda no início do filme, como aponta Daniel M. Delfino na crítica por ele escrita que "a primeira vítima de Dogville são as convenções estéticas da narrativa cinematográfica”. ${ }^{6}$ Mas convém mencionar que embora a exposição se dê no auge da depressão nos EUA dos anos de 1930 em que a violência dos gangsteres se faz muito presente e o local corresponda às instituiçôes e à cultura típica de uma cidade interiorana estadunidense, interessa-nos o ultrapassamento da situação bem como do local em que os acontecimentos se desenrolam, mantendo viva a indagação acerca das alternâncias de sentido do que seja o bem para os habitantes, pois a bondade de Dogville vai sendo transformada ao longo do filme, partindo das cores vibrantes da estação primaveril em exuberância de flores e odores até chegar às avassaladoras tempestades de um inverno rigoroso e implacável, fazendo esquecer os dias de outrora.

O filme, a nosso ver, leva-nos a compreender o argumento do diretor enquanto endereçando-se ao humano vivendo em conjunto; a todas as pessoas sensatas, prudentes, aquelas que seguem a moral judaico-cristã, mas também as que lhe atacam, quer dizer, a condição humana de estar no mundo e viver com os outros, sobreviver graças ao rebanho. Nesse sentido, fora de um tempo específico, já que extensivo à temporalidade humana. Se como aponta inicialmente Daniel Delfino a ausência de horizontes na cidade remete à inexistência de uma preocupação com o mundo exterior característica dos EUA que vê, como escreve o cronista, "o resto do mundo [como] uma imitação malfeita de seu país" , vemos como elemento central a vingança inconfessável atravessando todas as personagens em atuação e também aqueles que assistem ao filme. Nela percebemos a presença dos ideais ascéticos e do ressentimento nietzschianos expressos no desejo de defesa

6 Delfino, 20I8, acesso em I7/02/2018.

7 Delfino, 20I8, acesso em I7/02/2018. 
irrestrita da comunidade, da família, do jardim e no empenho ilimitado em destruir quem ataca e fere nossos ideais. Em Dogville, a imagem aparece invertida: a bela cidade, os bons cidadãos, as crianças educadas, o sábio, querendo conduzir a todos enquanto manifesta o sacerdote ascético, filantropo por natureza, ou, em termos nietzschianos, por autodefesa.

Correspondendo à moral de rebanho do tipo escravo nietzschiano, fundada pelo medo, a moral compartilhada pelos habitantes de Dogville teme a existência de tipos diferentes. A possibilidade de existência de tipos distintos assusta e, por isso, criam uma moral em defesa da coletividade, uma moral de rebanho. Não possuindo impulsos que possam elevá-lo acima da coletividade individualmente, optam por uma moral que generalize ao invés de particularizar. No limite, é uma reação de medo diante da diferença. Daí constituir-se em autodefesa. Ver o outro como responsável pela própria dor permite deslocar a compreensão do estado doente para o outro/senhor/forte que é visto como mau e réprobo até o fim enquanto o escravo/fraco/ressentido percebe-se, a partir disso, e somente desse modo, como bom.

Observe-se a personagem Tom com referências não tanto às ações, mas a ausência delas, já que o fazer dele é um constante postergar o que almeja e nunca realiza. Em nossa ótica, ele é típico ressentido, um tipo que manifesta uma vida sintomática de sua condição negadora. Como não consegue agir ou criar, atribui à negação essa possibilidade. Diz que o outro é mau para, a partir da negação do outro, sentir-se como bom, ainda que de forma aparente. Convém mencionar que em Nietzsche o ressentimento é a doença característica do tipo fraco/escravo que se define a partir dessa condição patológica. A anomalia, no escravo, é referida à impossibilidade de funcionamento do esquecimento e ao desenvolvimento exacerbado da memória que faz com que a ação propriamente dita não lhe seja característica e a forma correspondente seja a vingança imaginária. O ressentimento forma um tipo que para se definir precisa da existência de outro e da negação desse outro, equiparando, em vista disso, negar e criar. Com isso, compreende-se, de um lado, a sua incapacidade de reagir e, de outro, o estabelecimento do ódio como promotor da avaliação.

De outra parte, as personagens como um todo lutam pela vida de todas as formas, buscando amortecer o sofrimento, seja no trabalho, atividade maquinal, seja no auxilio mutuo, alegria do amor ao próximo. A atividade maquinal caracteriza-se pela concentração em atividades rotineiras que desviam a consciência da percepção da dor, produzindo um alívio, já que não permanece espaço para a depressão, uma vez que todo impulso é transferido para o fazer. Tratando-se do amor ao próximo, a necessidade de encobrimento do estado debilitado, bem como da dor que se lhe segue, leva os degradados a ajudarem ao outro. A partir 
disso, eles obtêm uma sensação de felicidade proveniente do sentir-se, em certa medida, superior. Para Nietzsche, todo ato de auxílio apresenta-se como consolo a esse tipo de vida, aos fisiologicamente obstruídos; por isso, manifestam uma tendência a se associarem, pois através da união, prestam auxilio e amor ao próximo, o que justamente tem por base uma estimulação da vontade de potência. Vemos, assim, o acolhimento de Grace sem outra necessidade que não a bondade característica de Dogville e ainda é a mesma condição e moral que está presente nas alternâncias manifestas no ódio radical, outrora latente e tornado público com relação a Grace, justificando, para os habitantes, todo esforço em aniquilá-la.

Há uma observação, presente nos textos de Nietzsche, apontando para a necessidade de proteger os sãos dos doentes, já que, para ele, "os doentes são o maior perigo para os sãos" ${ }^{8}$ Ora, em sua exposição, os fortes são temidos e venerados, enquanto os fracos são tidos por desprezíveis. Não obstante, através de uma vingança imaginaria, transformaram o senhor em escravo. O objetivo maior dos doentes é tornar todos doentes e, por isso, toda força, saúde, orgulho são vistos como algo depreciativo. Todavia, aparecem assim aos rancorosos, que mascaram a vingança e o rancor na forma de um novo amor, ocultando, com isso, o ódio presente no interpretar e avaliar. Desse modo, torna-se fundamental manter sempre presente a pergunta $\mathrm{O}$ que quer aquele que se alia e organiza os doentes? A resposta a essa questão permite identificar a vontade de nada, o niilismo, na base das postulações, e denunciar a sua vitória como um meio de introduzir a miséria mesmo nos fortes: "quando chegariam eles ao supremo, mais sutil e mais sublime triunfo da vingança? [...] quando eles conseguissem colocar sua própria miséria e toda miséria do mundo na consciência dos que são felizes", fazendo com que eles cheguem a se negar afirmando: "'é uma vergonha ser feliz! Há muita miséria" ”.

Os fortes, por conseguinte, colocam-se em uma situação paradoxal: infelizes diante da própria felicidade, envergonhados diante da própria força. Em vista disso, Nietzsche afirmar que eles têm de ser apartados dos fracos para evitar o seu adoecimento, cuja manifestação máxima será "o grande nojo e a grande compaixão pelo homem”. Se os fortes não podem se juntar aos fracos, então não cabe a eles igualmente tratá-los. Há uma impossibilidade natural de transpor o pathos da distância, o que torna impossível ao senhor rebaixar-se a escravo ou tornar-se instrumento dele, ainda que como curandeiro, pressupondo que isso fosse possível, já que o tipo senhor não é imune ao nojo, como Grace não o é.

A narrativa de Trier mostra-nos isso através do adoecimento da personagem central que vai perdendo a habilidade de olhar para frente, de desvencilhar-se

8 Genealogia da Moral, "Terceira dissertação", $\$$ I4, KSA 5.367, tradução de RRTF.

9 Genealogia da Moral, "Terceira dissertação", $₫$ I4, KSA 5.370-37I, tradução de RRTF. 
através do esquecimento de todo malefício sofrido. Ela começa a ter chagas, manifestas na imobilidade do corpo enquanto uma tentativa de estancar a doença já viva, mas agindo lentamente. Na perspectiva nietzschiana, há uma certa normalidade na condição doentia do homem, uma certa constância de condição. Em diversas épocas, ele manifesta um fastio diante da vida, expressando, com isso, um descontentamento de si mesmo. Apesar de configurar-se como o indomado, o insaciável, aquele que quer dominar o mundo determinando a natureza e Deus, é igualmente o mais suscetível ao adoecimento de si, ao fastio diante da vida, e isso como decorrência da dificuldade e, quiçá, impossibilidade de assimilar a transformação radical que sofreu, quando se viu encerrado no âmbito da sociedade e da paz, internalizando os impulsos outrora sem amarras. Somente em casos raros isso não se processa: "Se a morbidez é tão normal no homem - e isso é incontestável - então se deveria ainda mais estimar os raros casos de poder da alma e do corpo, os golpes certeiros do gênero humano, e proteger mais intensamente os seres bem-sucedidos contra a atmosfera maligna dos doentes". ${ }^{\circ}$

Voltando ao filme, basta observar que se os habitantes de Dogville concordam em eliminar a heroína ao entregá-la aos gangsteres, acordando com a eliminação do adversário sempre de prontidão para revelar o espelho sem inversões que os permitia se verem de outro modo, Grace termina destruindo a cidade e, com isso, reproduzindo a ação das personagens que julgava diferir por completo. Em ambos os casos, está presente a má Éris que põe termo à disputa ao eliminar o adversário, apontando para o adoecimento completo de Grace ao fim da narrativa.

Convém trazer para nossa análise outro conceito nietzschiano, o de luta que se encontra presente em todos os momentos do discurso dele, expressando sempre o movimento, embora com acréscimos e contornos diferenciados ao longo da elaboração da obra. A luta, como conceito fundamental, está presente nas relações entre os impulsos em cada homem e nas relaçôes de disputa entre os homens, que lutam para estabelecer a hegemonia de valores e impor uma interpretação, mas nunca visando à destruição ou ao aniquilamento do adversário que, no limite, enquanto forte, é temido e venerado. Tomemos o texto A Disputa de Homero em que a luta aparece como disputa, resgatando o sentido do agon grego presente na Ilíada quando do combate entre os heróis helenos. Trata-se de compreender a disputa como qualidade, enquanto atua estimulando os homens à ação e jamais conduzindo ao aniquilamento do outro, pois é uma boa Éris, como diz Hesíodo, que conduz os homens sem hostilidade e sem aniquilação, como em um jogo que determina sempre a continuidade da disputa. Somente a má Éris dirige uma luta que destrói, aniquila e mata o adversário. Em Nietzsche, esse é o desejo não

IO Genealogia da Moral, "Terceira dissertação", $\$ I4, KSA 5.367, tradução de RRTF. 
manifesto do tipo escravo e é ele que vemos reger as ações em Dogville e também o desejo confesso de Grace no final dele.

\section{Mas e o nosso desejo? Quanto de verdade suportamos?}

Em nossa ótica, vemos nosso desejo no desejo de Grace, manifestamos nossa doença ao assistir ao filme, mostrando de modo iniludível que nem ela e nem nós somos imunes ao ressentimento e aos ideais ascéticos. Ao final de Dogville, expomos o brilho sutil de nossas chagas supurantes com a satisfação que sentimos quando a cidade é destruída, mesmo a morte das crianças nos parece pertinente, afinal, Dogville é má e o mundo seria melhor sem ela. Trier através de Dogville nos dá de presente um espelho incapaz de inversão, sem que percebamos damos vazão ao nosso desejo de aniquilar o inimigo, aquele que nos fere, processa-se a remoção lenta do véu silencioso de nossa inconfessável vingança, congratula-mo-nos com Grace da missão necessária de destruir Dogville e, ao fazê-lo, nossa humanidade fracassa, damos vazão irrestrita à nossa Santa Ira, queremos iniludivelmente a morte de Dogville, mostrando o entrelaçamento apontado por Nietzsche entre humanidade e doença.

Em Para além de Bem e Mal, Nietzsche escreve: "quase tudo o que chamamos de 'civilização superior' repousa sobre a espiritualização e o aprofundamento da crueldade: tal é a minha tese. Esse 'animal feroz' não foi, de forma alguma, abatido: ele vive e prospera, ele apenas... se divinizou". " $\mathrm{Na}$ compreensão do filósofo, a espiritualização da crueldade não a exclui, apenas a transforma. Mas há um ponto interessante a ressaltar referente à crueldade, pois a sua exaltação dela, na visão nietzschiana, não visa jamais ao pessimismo diante da vida. Bem pelo contrário, em todas as épocas em que a humanidade associava a crueldade à festa e à alegria, seja para o prazer dos deuses "Qual foi, no fundo, o sentido da guerra de Tróia e de outros horrores trágicos semelhantes? Sem dúvida, foram jogos para deleitar os deuses" ${ }^{\prime 2}$, seja dos homens, sem incutir nela um valor depreciativo, não havia pessimismo na avaliação da vida. A existência era mais leve e alegre quando o homem não se envergonhava de seus impulsos. $\mathrm{O}$ peso e o pessimismo estão diretamente relacionados com o homem domesticado, aquele que nega a vida e os instintos, promovendo o pessimismo e o niilismo que surgem a partir da moralização das noções de 'culpa', 'consciência', 'dever' e dos demais valores da moral judaico-cristã, que vê nas manifestaçôes espontâneas do homem algo imoral e, com isso, decreta a vergonha do homem diante do homem.

II Para além de Bem e Mal $\$$ 229, KSA 5.I66. Tradução conforme Paulo Cesar Souza (Nietzsche, 1992).

I2 Genealogia da Moral, "Segunda dissertação", $\$$ 7, KSA 5.304, tradução de RRTF. 
Ao sublimar a crueldade, transpondo-a ao plano imaginário o homem inaugura a cisão da consciência e o mal-estar da humanidade, fazendo com que a força do impulso e os efeitos decorrentes da suspensão dele determinem a doença na condição humana. Um ensaio inverso seria possível? Sim, mas nesse caso, nietzschianamente, teríamos transvalorado os valores de nossa cultura, superado a moral judaico-cristã, nos colocado para além de bem e mal e verdade e erro, situado o valor nessa vida, ultrapassado o homem, criando pelo prazer de criar e destruindo pelo prazer de destruir, e nos situando para além-do-homem. Afinal, como afirma Nietzsche:

O homem é uma corda estendida entre o animal e além-do-homem - uma corda sobre um abismo. É o perigo de transpô-lo, o perigo de estar a caminho, o perigo de olhar para trás, o perigo de tremer e parar. O que há de grande, no homem, é ser ponte, e não meta: o que pode amar-se, no homem, é ser uma transição e um ocaso. ${ }^{\text {I3 }}$

\section{Referências}

Azeredo, V. D. Nietzsche e a dissolução da moral. $2^{\mathrm{a}}$ ed. São Paulo: Unijuí: Discurso, 2003 .

Delfino, D. 'Dogville' e a morte do humanismo. Espaço Socialista. http://espacosocialista.org/portal/2008/12/dogville-e-a-morte-do-humanismo. Acesso em I7/02/2018.

GEN. Dicionário Nietzsche. São Paulo: Loyola, 2016.

NiEtzsche, F. Sämtliche Werke - Kritische Studienausgabe, edição organizada por Giorgio Colli e Mazzino Montinari. Berlim: Walter de Gruyter \& Co., 1967/1978. 15 vol.

Nietzsche, F. Nietzsche - Obras Incompletas, coleção "Os Pensadores", tradução de Rubens Rodrigues Torres Filho, São Paulo: Abril Cultural, 1978.

Nietzsche, F. Assim falou Zaratustra. Trad. Mario da Silva. Rio de Janeiro: Civilização Brasileira, I98I.

Nietzsche, F. Para além de bem e mal, Trad. Paulo César Souza, São Paulo: Companhia das Letras, 1992.

I3 Nietzsche, Assim falava Zaratustra, "Prólogo", \$4, KSA 4.I6. Tradução conforme Mário da Silva (Nietzsche, I98I). 